\title{
IgG4-associated cholangitis: a comparative histological and immunophenotypic study with primary sclerosing cholangitis on liver biopsy material
}

\author{
Vikram Deshpande ${ }^{1}$, Nisha I Sainani ${ }^{2}$, Raymond T Chung ${ }^{4}$, Daniel S Pratt ${ }^{4}$, \\ Gilles Mentha ${ }^{5}$, Laura Rubbia-Brandt ${ }^{3}$ and Gregory Y Lauwers ${ }^{1}$ \\ ${ }^{1}$ The James Homer Wright Pathology Laboratories, Massachusetts General Hospital, Harvard Medical School, \\ Boston, MA, USA; ${ }^{2}$ Department of Radiology, Massachusetts General Hospital, Harvard Medical School, \\ Boston, MA, USA; ${ }^{3}$ Department of Pathology, University Hospital, Geneva, Switzerland; ${ }^{4}$ Gastrointestinal \\ Unit, Department of Medicine, Massachusetts General Hospital, Harvard Medical School, Boston, MA, USA \\ and ${ }^{5}$ Division of Visceral and Transplantation Surgery, University Hospital, Geneva, Switzerland
}

IgG4-associated cholangitis is a steroid-responsive hepatobiliary inflammatory condition associated with autoimmune pancreatitis that clinically and radiologically mimics primary sclerosing cholangitis. In this study, we conducted a morphological and immunohistochemical analysis of liver material obtained from individuals with IgG4-associated cholangitis, and compared these with well-characterized cases of primary sclerosing cholangitis. The study group consisted of 10 patients ( 9 biopsy and 1 hepatectomy case) with IgG4-associated cholangitis and 17 patients with primary sclerosing cholangitis (16 needle biopsy and 1 hepatectomy case). All patients with IgG4-associated cholangitis had pancreatic involvement as well, and six pancreatectomy samples revealed characteristic histopathological features of autoimmune pancreatitis. Primary sclerosing cholangitis cases were defined by the presence of a characteristic ERCP appearance. Clinical, pathological, radiological, and follow-up data were recorded for all cases. Portal and periportal inflammation was graded according to Ishak's guidelines. Immunohistochemical stains for IgG and IgG4 were performed. The cohort of patients with IgG4-associated cholangitis (mean age: 63 years) was older than individuals with primary sclerosing cholangitis (mean age: $\mathbf{4 4}$ years). Seven of these cases showed intrahepatic biliary strictures. IgG4-associated cholangitis liver samples showed higher portal $(P=0.06)$ and lobular $(P=0.009)$ inflammatory scores. Microscopic portal-based fibro-inflammatory nodules that were composed of fibroblasts, plasma cells, lymphocytes, and eosinophils were exclusively observed in five of the IgG4-associated cholangitis cases (50\%). More than 10 IgG4-positive plasma cells per HPF (high power field) were observed in 6 of the IgG4associated cholangitis cases (mean: 60, range: 0-140 per HPF), whereas all primary sclerosing cholangitis cases showed significantly lesser numbers (mean: 0.08 , range: $0-1$ per HPF). On a liver biopsy, the histological features of IgG4-associated cholangitis may be distinctive, and in conjunction with IgG4 immunohistochemical stain, may help distinguish this disease from primary sclerosing cholangitis.

Modern Pathology (2009) 22, 1287-1295; doi:10.1038/modpathol.2009.94; published online 24 July 2009

Keywords: autoimmune pancreatitis; primary sclerosing cholangitis; IgG4; IgG4 associated cholangitis

Correspondence: Dr Vikram Deshpande, MD, Gastrointestinal Pathology Service, Department of Pathology, Warren 2, Massachusetts General Hospital, 55 Fruit Street, Boston, MA 02114, USA.

E-mail: VDESHPANDE@PARTNERS.ORG

Received 16 March 2009; revised and accepted 26 May 2009; published online 24 July 2009
Primary sclerosing cholangitis is a cholestatic disease characterized by patchy inflammation, fibrosis, and stricturing of the intrahepatic and/or extrahepatic bile ducts. ${ }^{1}$ The diagnosis of primary sclerosing cholangitis is based on characteristic cholangiographic findings, in combination with clinical, biochemical, and histological features. The disease lacks a definitive etiological factor, 
although a strong association with inflammatory bowel disease is well recognized. It must be noted that, patients with concomitant ulcerative colitis are at an increased risk for cholangiocarcinoma. ${ }^{1}$ The disease typically does not respond to immunosuppressive therapy, and hepatic transplantation continues to be the only option to provide long-term survival benefit in these patients. ${ }^{2}$

The term 'secondary sclerosing cholangitis' is used to designate cases in which a specific etiological factor is identified..$^{3-5}$ The causes of secondary sclerosing cholangitis include autoimmune pancreatitis-associated sclerosing cholangitis, eosinophilic cholangiopathy, mast cell cholangiopathy, and AIDS cholangiopathy. ${ }^{3-5}$ Among these, autoimmune pancreatitis-associated sclerosing cholangitis has recently received significant attention, in part, because of the steroid-responsive nature of this disease. $^{4,6,7}$ Similar to manifestations of IgG4-associated disease, autoimmune pancreatitis-associated sclerosing cholangitis shows increased numbers of IgG4-positive plasma cells, justifying the recently suggested nomenclature of IgG4-associated cholangitis. $^{6}$

As IgG4-associated cholangitis is a steroid-responsive process, whereas primary sclerosing cholangitis is typically steroid resistant, it is thus vital for management to distinguish IgG4-associated cholangitis from primary sclerosing cholangitis. Consequently, our goal was to determine whether this distinction could be made on a liver biopsy.

\section{Materials and methods}

\section{Study Group}

We identified nine liver biopsy samples of patients with autoimmune pancreatitis obtained from the files of the Massachusetts General Hospital (Boston, MA) and a liver explant from an individual with autoimmune pancreatitis from l'Hopitâl Universitaire de Geneve. In this study, a diagnosis of autoimmune pancreatitis required the involvement of the pancreas, either on histopathological or on imaging grounds.

\section{Group of Primary Sclerosing Cholangitis}

A series of 16 consecutive needle liver biopsy samples and 1 explant from patients with cholangiographically confirmed primary sclerosing cholangitis cases were also accrued.

Follow-up information and therapeutic details were recorded for all patients.

\section{Histopathology}

The pathologists were blinded to the final diagnosis. All biopsy samples and the single explant were evaluated for the intensity, location, and character- istic of the inflammatory infiltrate using the Ishak scoring system. Fibrosis was evaluated on a 1-4 scale, using a scoring system that was developed for primary sclerosing cholangitis. ${ }^{8}$

\section{Immunohistochemistry}

Tissue immunostaining using monoclonal antihuman IgG4 antibody and IgG was performed as reported previously on 10 IgG4-associated cholangitis cases and on 12 primary sclerosing cholangitis cases. $^{9}$ Briefly, immunohistochemistry was performed using mouse monoclonal antibodies against human IgG4 (Zymed, Carlsbad, CA, USA; dilution: 1:200) and IgG (Dako, Glostrup, Denmark; dilution: $1: 8000)$ using the avidin-biotin immunoperoxidase method. The liver biopsy samples obtained from the other primary sclerosing cholangitis cases entirely lacked inflammatory cells, and hence immunohistochemistry was not performed on these cases. A maximum of $10 \mathrm{HPF}$ (high power field) yielding the highest number of IgG4 plasma cells were evaluated on a Zeiss Axioskop microscope. The numbers of IgG-positive plasma cells were enumerated in the same fields. An average of these counts was determined. A ratio of IgG4 to IgG was also derived.

\section{Cholangiographic Studies}

Available cholangiograms (endoscopic retrograde cholangiopancreatography $(n=15)$ and magnetic resonance cholangiopancreatography $(n=11))$ were reviewed by a single radiologist. Strictures were characterized as intrahepatic, hilar, and extrahepatic.

\section{Statistics}

Statistics were calculated using SPSS version 15.0 (SPSS, Chicago, IL, USA). Differences between groups were evaluated using the $\chi^{2}$ test or the Fisher exact test for qualitative variables, and the Student $t$-test for quantitative variables. A $P$-value $<0.05$ was considered significant.

\section{Results}

\section{Demographic and Clinical Details}

Patients with IgG4-associated cholangitis (age: 4280 years, mean: 63) were significantly older than those with primary sclerosing cholangitis (mean: 44 years $)(P=0.006)$. Both groups showed a male preponderance. The majority of patients $(70 \%)$ with IgG4-associated cholangitis presented with obstructive jaundice. The serum IgG4 level was increased in all four IgG4-associated cholangitis cases, in which it was evaluated (Tables 1 and 2). 


\section{Imaging Data}

Five patients with IgG4-associated cholangitis showed multiple right and left intrahepatic duct strictures with segmental dilatation (Figure 1). Two patients presented with hilar strictures and intrahepatic ductal dilatation. One patient had a long segment stricture of the mid and distal common bile duct with attenuation of intrahepatic biliary radicals. In two cases, the cholangiograms that were conducted at an outside institution were read as showing only intrapancreatic bile duct strictures.

All 17 primary sclerosing cholangitis cases showed multiple strictures with segmental dilatation (beaded appearance) of the right and left intrahepatic ducts. In addition, six patients had hilar strictures and five showed multifocal extrahepatic duct strictures. Blinded to the final diagnosis, the radiologist was unable to make a definitive distinction between IgG4-associated cholangitis and primary sclerosing cholangitis.

Table 1 Comparative demographic and liver enzyme levels

\begin{tabular}{lcc}
\hline & $\begin{array}{c}\text { IgG4-associated } \\
\text { cholangitis } \mathrm{n}=10\end{array}$ & $\begin{array}{c}\text { Primary sclerosing } \\
\text { cholangitis } \mathrm{n}=17\end{array}$ \\
\hline Median age & 63 & 44 \\
Sex & $8: 2$ & $14: 3$ \\
AST $^{\mathrm{a}}$ & $74(113)$ & $98(76)$ \\
Alkaline $_{\text {phosphatase }^{\mathrm{a}}}$ & $303(424)$ & $392.5(448)$ \\
Total bilirubin $^{\mathrm{a}}$ & $1.3(6.3)$ & $1.2(2.6)$ \\
$\begin{array}{l}\text { Direct bilirubin } \\
\text { Ulcerative }\end{array}$ & $0.7(6)$ & $0.6(2.4)$ \\
colitis/Crohn's $^{\text {a }}$ & $1 / 1$ & $6 / 3$ \\
\hline
\end{tabular}

AST, aspartate aminotransferase; IgG, immunoglobulin G.

${ }^{\mathrm{a}}$ Median. Numbers in parenthesis indicate the interquartile range.

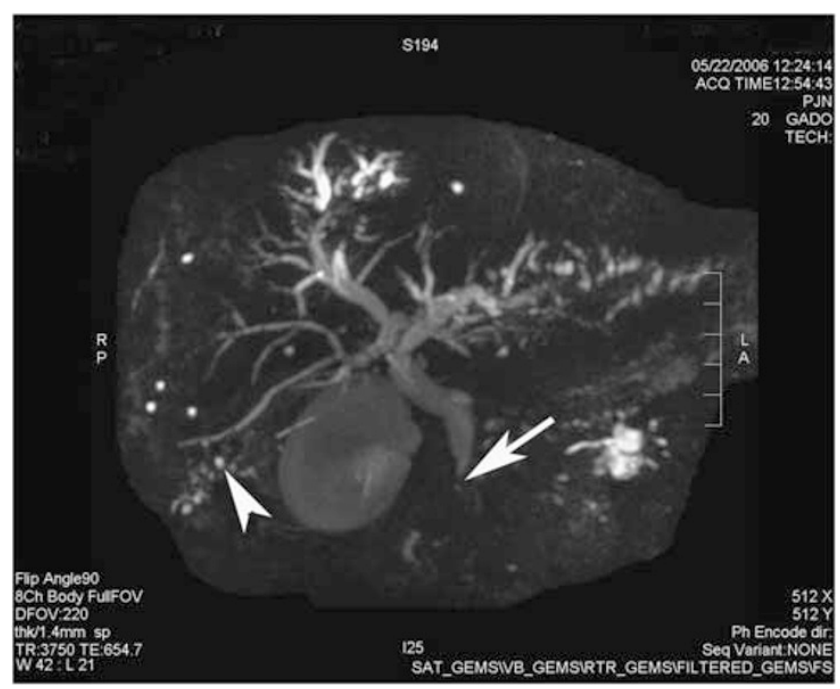

Figure 1 Magnetic resonance cholangiopancreatography of a patient with IgG4-associated cholangitis showing diffuse beading and stricturing of bile ducts (arrow head). The distal bile duct stricture (arrow) is also noted.
Evidence of autoimmune pancreatitis in the IgG4-associated cholangitis group

In seven cases, the diagnosis of autoimmune pancreatitis was made not only on the basis of clinical information and radiological findings but was also confirmed on histological evaluation of a pancreatic resection specimen $(n=6)$ and a sole pancreatic biopsy sample $(n=1)$. In cases 6 and 8 (Table 2), the diagnosis was established on clinical and radiological grounds, and on a complete response to steroids. One patient (case no. 7) initially presented with multiple renal masses that on biopsy showed features of autoimmune pancreatitis-associated renal disease (this case has been reported previously ${ }^{10}$ ). Multiple intrahepatic biliary strictures were also noted on an MRI. Subsequently, a diffuse enlargement of the pancreas was identified. An increased number of IgG4-positive plasma cells was documented in the IgG4-associated cholangitis group both within the pancreas and extra-pancreatic locations as indicated in Table 2.

\section{Pathological Findings}

Macroscopic evaluation. On gross examination, the sole explant showed a fleshy portal-based mass with several small peripheral hepatic nodules (Figure 2a).

Microscopic evaluation. Inflammatory component: A detailed analysis of the histological features is presented in Table 3. In comparison with the primary sclerosing cholangitis cohort, portal $(P=0.06)$, lobular $(P=0.009)$, and zone $3(P=0.2$, NS) inflammatory infiltrates were more prominent in the IgG4-associated cholangitis cases. The portal inflammatory infiltrate was composed of lymphocytes, plasma cells, and eosinophils, the latter two cell types were significantly more frequently identified in the IgG4associated cholangitis group (Figure 3a). The portalbased infiltrate in IgG4-associated cholangitis tended to spare the bile ducts, generating a paucicellular halo around the bile ducts (Figure 3b). Furthermore, perivenular accentuation (50\%) of the inflammatory infiltrate was noted in the portal tracts of biopsy samples that were obtained from individuals with IgG4-associated cholangitis (Figure 3b). Focal and patchy interface hepatitis was recognized in both groups. The majority of IgG4-associated cholangitis cases $(70 \%)$ also showed a lobular inflammatory component, a finding that was significantly less common in primary sclerosing cholangitis. The lobular infiltrate was composed of lymphocytes with scattered plasma cells and eosinophils. Although rare foci of hepatocytic dropout were observed, apoptotic bodies were visualized only rarely. In addition, in three IgG4-associated cholangitis cases $(30 \%)$, the inflammatory infiltrate was accentuated in zone 3 . However, there was no evidence of destructive or obliterative phlebitis in the biopsy samples.

It must be noted that, we recognized five cases of IgG4-associated cholangitis that showed 
Table 2 Demographic and clinical features of IgG4-associated cholangitis cases

\begin{tabular}{|c|c|c|c|c|c|c|c|c|c|c|c|c|c|}
\hline & Age & Sex & $\begin{array}{l}\text { Presenting } \\
\text { symptoms }\end{array}$ & $\begin{array}{l}\text { Resection and } \\
\text { biopsies }\end{array}$ & $A L T$ & $\begin{array}{l}\text { Alkaline } \\
\text { Phosp- } \\
\text { hatase }\end{array}$ & $\begin{array}{l}\text { Total bili- } \\
\text { rubin }\end{array}$ & $\begin{array}{l}\text { Other } \\
\text { manifestations }\end{array}$ & $\begin{array}{l}\text { Cholangiographic } \\
\text { findings }\end{array}$ & $\begin{array}{l}\text { Sequence of liver/ } \\
\text { pancreatic } \\
\text { involvement }\end{array}$ & $\begin{array}{l}\text { Tissue IgG4 } \\
\text { cells per HPF } \\
\text { in liver }\end{array}$ & $\begin{array}{l}\text { Serum IgG4/ } \\
\operatorname{Ig} G\end{array}$ & Follow-up \\
\hline 1 & 59 & M & $\begin{array}{l}\text { Obstructive } \\
\text { jaundice } \\
\text { Diarrhea Weight } \\
\text { loss }\end{array}$ & Whipple $^{\mathrm{a}}$ & 41 & 108 & 0.8 & None & $\begin{array}{l}\text { Long } \\
\text { intrapancreatic } \\
\text { CBD stricture }\end{array}$ & Synchronous & 49 & NA & $\begin{array}{l}\text { LTFU } \\
\text { No steroid use }\end{array}$ \\
\hline 2 & 73 & M & $\begin{array}{l}\text { Obstructive } \\
\text { jaundice }\end{array}$ & Whipple ${ }^{\mathrm{a}}$ & 175 & 469 & 21.3 & None & $\begin{array}{l}\text { Multisegmental } \\
\text { obstruction right, } \\
\text { left and CBD }\end{array}$ & $\begin{array}{l}\text { Post } \\
\text { pancreatectomy }\end{array}$ & 123 & NA & $\begin{array}{l}\text { No steroid use } \\
\text { Biliary cirrhosis } \\
\text { Death of disease } \\
24 \text { months after } \\
\text { pancreatectomy }\end{array}$ \\
\hline 3 & 79 & $\mathrm{~F}$ & $\begin{array}{l}\text { Obstructive } \\
\text { jaundice weight } \\
\text { loss }\end{array}$ & $\begin{array}{l}\text { Pancreas biopsy } \\
\text { Cholecystectomy }\end{array}$ & 194 & 555 & 1.7 & None & $\begin{array}{l}\text { Intrapancreatic } \\
\text { CBD stricture }\end{array}$ & Synchronous & 1 & NA & $\begin{array}{l}\text { LTFU } \\
\text { No steroid use }\end{array}$ \\
\hline 4 & 80 & M & Diarrhea & Whipple $^{\mathrm{a}}$ & 90 & 118 & 1.3 & $\begin{array}{l}\text { Guillian Barre, } \\
\text { Ulcerative colitis }\end{array}$ & C/W PSC & $\begin{array}{l}\text { Post } \\
\text { pancreatectomy }\end{array}$ & 0 & 1430/NA & $\begin{array}{l}\text { No steroids. } \\
\text { urodiol } \\
\text { LTFU }\end{array}$ \\
\hline 5 & 78 & M & $\begin{array}{l}\text { Obstructive } \\
\text { jaundice }\end{array}$ & $\begin{array}{l}\text { Bile duct resection } \\
\text { followed by } \\
\text { Whipple }^{\mathrm{a}}\end{array}$ & 19 & 105 & 0.4 & Kidney & $\begin{array}{l}\text { Long CBD } \\
\text { stricture, } \\
\text { attenuated left } \\
\text { intrahepatic duct }\end{array}$ & $\begin{array}{l}\text { Pre- } \\
\text { pancreateatetomy }\end{array}$ & 0 & $2420 / \mathrm{NA}$ & $\begin{array}{l}\text { Dead of other } \\
\text { causes } \\
\text { No steroid use }\end{array}$ \\
\hline 6 & 57 & M & $\begin{array}{l}\text { Obstructive } \\
\text { jaundice }\end{array}$ & Bile duct biopsy, & 106 & 1432 & 10.6 & $\begin{array}{l}\text { Lunga, lymph } \\
\text { nodes gallbladder }\end{array}$ & $\begin{array}{l}\text { Multiple } \\
\text { intrahepatic bile } \\
\text { duct strictures }\end{array}$ & Synchronous & 115 & $5570 / \mathrm{NA}$ & $\begin{array}{l}\text { Normalization of } \\
\text { liver function tests } \\
\text { on maintenance } \\
\text { dose of } 5 \mathrm{mg} \\
\text { steroids; unable to } \\
\text { wean }\end{array}$ \\
\hline 7 & 58 & $\mathrm{~F}$ & Enlarged liver & Kidney biopsy ${ }^{\mathrm{a}}$ & 56 & 473 & 0.5 & Kidney $^{a}$ & $\begin{array}{l}\text { Concentric area of } \\
\text { narrowing of the } \\
\text { confluence of } \\
\text { right and left bile } \\
\text { ducts with } \\
\text { surrounding mass } \\
\text { on T2 signal }\end{array}$ & $\begin{array}{l}\text { Liver involvement } \\
\text { was primary } \\
\text { manifestation }\end{array}$ & 43 & NA & $\begin{array}{l}\text { Normalization of } \\
\text { liver function tests } \\
\text { on urodiol }\end{array}$ \\
\hline 8 & 68 & M & $\begin{array}{l}\text { Obstructive } \\
\text { jaundice }\end{array}$ & $\begin{array}{l}\text { Mediastinal } \\
\text { lymph node } \\
\text { biopsy }\end{array}$ & 57 & 158 & 1.3 & $\begin{array}{l}\text { Salivary gland }{ }^{\mathrm{a}} \\
\text { retroperitoneal }\end{array}$ & $\begin{array}{l}\text { T2 signal } \\
\text { abnormality with } \\
\text { vague mass, } \\
\text { alternate } \\
\text { narrowing and } \\
\text { dilatation of } \\
\text { intrahepatic bile } \\
\text { duct radicals }\end{array}$ & $\begin{array}{l}\text { Liver involvement } \\
\text { was primary } \\
\text { manifestation }\end{array}$ & 37 & $4160 / 3580$ & $\begin{array}{l}\text { Complete } \\
\text { biochemical } \\
\text { response of liver } \\
\text { function tests on } \\
\text { steroids }\end{array}$ \\
\hline 9 & 42 & $\mathrm{~F}$ & $\begin{array}{l}\text { Hepatic hilar } \\
\text { mass }\end{array}$ & Whipple ${ }^{a}$ & NA & NA & NA & None & NA & $\begin{array}{l}\text { Post } \\
\text { pancreatectomy }\end{array}$ & 140 & NA & No steroid use \\
\hline 10 & 75 & M & $\begin{array}{l}\text { Obstructive } \\
\text { jaundice }\end{array}$ & $\begin{array}{l}\text { Whipple and } \\
\text { retroperitoneal } \\
\text { biopsy }\end{array}$ & 61 & 346 & 0.2 & None & $\begin{array}{l}\text { Diffusely irregular } \\
\text { intrahepatic } \\
\text { ductal system, } \\
\text { with areas of } \\
\text { beading and } \\
\text { saccular dilatation }\end{array}$ & $\begin{array}{l}\text { Post } \\
\text { pancreatectomy }\end{array}$ & 1 & NA & $\begin{array}{l}\text { Normalization of } \\
\text { liver function tests } \\
\text { on steroids; } \\
\text { resolution of } \\
\text { retropancreatic } \\
\text { masses }\end{array}$ \\
\hline
\end{tabular}

ALT, alanine transaminase; CBD, common bile duct; F, female; HPF, high power field; IgG, immunoglobulin G; LTFU, lost to follow-up; M, male; PSC, primary sclerosing cholangitis; NA, Not Available.

${ }^{\mathrm{a}}$ Elevated numbers ( $>10$ per HPF) numbers of IgG4-positive plasma cells were documented in these lesions at an extrahepatic location. 
microscopic portal-based fibro-inflammatory nodules, a feature absent in the primary sclerosing cholangitis cohort (Figures 2b, 4a and b). These expansile nodules, which were not seen in the primary sclerosing cholangitis cohort, were located within portal tracts and comprised lymphocytes, plasma cells, eosinophils, and fibroblasts. ${ }^{9,10}$ They were frequently associated with a myxoid stroma. In fact, these distinctive nodules resembled autoimmune pancreatitis-associated pseudotumors observed in the pancreas and in other organs. ${ }^{9,10}$

Bile ductular reduplication and onion skin-type fibrosis were noted in both primary sclerosing cholangitis and IgG4-associated cholangitis. Significantly, there appeared to be no difference in the stage of fibrosis between the two groups.

\section{IgG and IgG4 immunohistochemical analysis}

In all, 8 the 10 IgG4-associated cholangitis cases showed at least a single IgG4-positive cell per HPF (mean: 60, range: 0-140), whereas only a single primary sclerosing cholangitis case showed IgG4-positive cells ( 1 per HPF; Figure $2 \mathrm{~d}$ and e). More than 10 IgG4-positive plasma cells per HPF were observed in six $(n=6)$ IgG4-associated cholangitis cases, whereas all primary sclerosing cholangitis cases showed lesser numbers of IgG4positive cells.

The IgG4-associated cholangitis cases not only showed a significantly higher number of IgG4positive cells but also significantly higher IgG4 to IgG ratios. The IgG4-positive cells were recognized predominantly within portal tracts, although occasionally zone 3 plasma cells were also identified. Furthermore, the IgG4-associated cholangitis cases showed a significantly higher number of IgGpositive plasma cells $(P=0.02)$. However, within a liver biopsy, there was marked heterogeneity in the degree of involvement, with several portal tracts in each biopsy entirely lacking IgG4 cells.

Five pancreatectomy specimens were classified as autoimmune pancreatitis of either ductocentric or lobulocentric type, as described previously. ${ }^{9}$ Four of the pancreatic resections were of the ductocentric type, and one of the lobulocentric type. The median hepatic IgG4 count in the ductocentric cohort was 34 per HPF (range: 0-123), whereas the sole lobulocentric-type AIP showed 49 IgG4-positive plasma cells per HPF.

\section{Treatment and outcome of IgG4-associated cholangitis cases}

Three of the IgG4-associated cholangitis patients (nos 6, 8, and 10) were treated with steroids and underwent normalization of liver function tests (Table 2). In addition, two patients have been treated with ursodiol, including one with normalization of liver function tests.

\section{Discussion}

Our understanding of what was once regarded as an autoimmune pancreatic disease has evolved significantly over the last decade, and extra-pancreatic manifestations of this IgG4-associated disease are being increasingly recognized. ${ }^{11}$ All lesions incorporated into the spectrum of the disease, including the pancreatic manifestations are characterized by a plasma cell-rich, often mass-forming inflammatory process with numerous IgG4-positive plasma cells. ${ }^{11}$ In a recent publication, Ghazale et $a l^{6}$ proposed the term 'IgG4-associated cholangitis' to describe the biliary manifestation of autoimmune pancreatitis. Although we acknowledge that this new terminology is not universally accepted, our findings and those of previous investigators support this nomenclature. ${ }^{12}$

Primary sclerosing cholangitis mimics IgG4-associated cholangitis both clinically and cholangiographically, and this study attempts to provide histological clues that could distinguish the two conditions, and thus potentially identify this steroid-responsive subset of sclerosing cholangitis. An additional reason for making this distinction is that, given the absence of well-documented cases of malignant transformation to date, the risk of a cholangiocarcinoma in individuals with IgG4-associated cholangitis is likely significantly lower than for those with primary sclerosing cholangitis.

In this study, we compared 9 liver biopsy samples and a hepatic explant obtained from patients with IgG4-associated cholangitis with 16 consecutive biopsy samples and 1 hepatectomy specimen from well-characterized individuals with primary sclerosing cholangitis. Six $(n=6)$ of the nine biopsy samples that were studied were non-focal biopsy samples, whereas two were directed at ill-defined mass lesions.

In our group, although admittedly a smaller series, the clinical profile of the patients is remarkably similar to that of Ghazale et al's. Patients with IgG4associated cholangitis are generally older men $(85 \%)$, presenting with obstructive jaundice $(77 \%)$ and autoimmune pancreatitis (92\%). ${ }^{6}$ On imaging, the biliary strictures are confined to the intrapancreatic bile duct in $51 \%$ of the cases, but the proximal extrahepatic bile and intrahepatic branches are involved in $49 \%$ of the cases. ${ }^{6}$ Importantly, in one series, the majority of strictures responded to steroids, although relapses were common after withdrawal. ${ }^{6}$ However, although it has been reported by some that imaging studies may help segregate IgG4-associated cholangitis from primary sclerosing cholangitis, in our experience we were unable to make this distinction. ${ }^{13}$

We report that some morphological features may allow the distinction of primary sclerosing cholangitis from IgG4-associated cholangitis. The IgG4associated cholangitis liver samples presented with a dense inflammatory infiltrate that is not only 

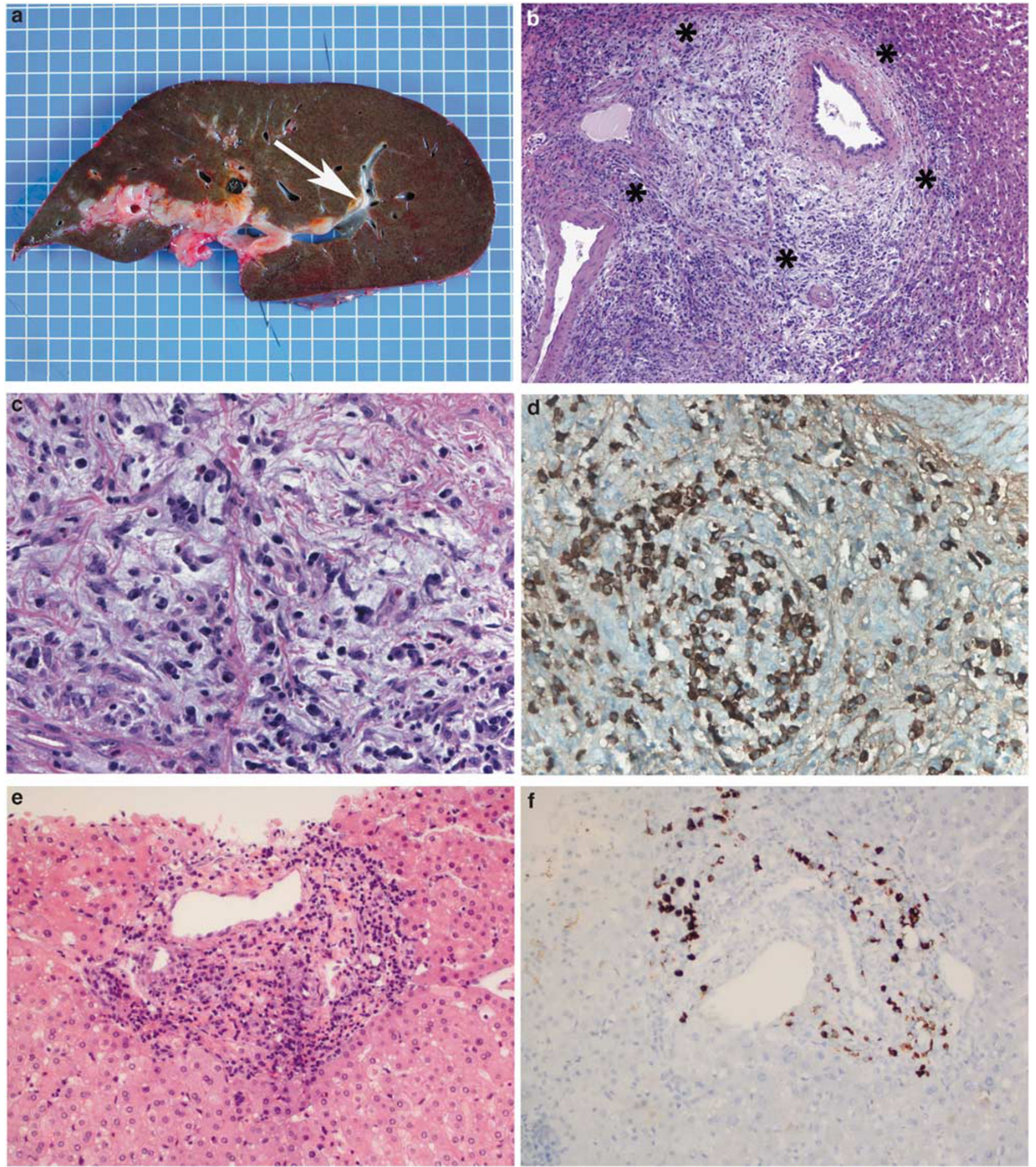

Figure 2 (a) IgG4-associated cholangitis explant with hilar mass and multiple peripheral nodules (arrow). (b) Portal inflammatory nodule ( ${ }^{*}$ highlights the outlines of this expansive nodule). (c) High power of panel b. The edematous and myxoid stroma with lymphocytes and plasma cells is noted. (d) Numerous IgG4-positive cells. (e) Smaller portal tract than in panel a with lymphocytes and plasma cells and IgG4-positive plasma cells (f).

portal based but also involve the lobules with the occasional involvement of zone 3. Within the portal tracts, the infiltrate accentuates around the hepatic venules and tends to spare bile ducts. This perivenular involvement is reminiscent of the phlebitis observed in other IgG4-associated diseases. ${ }^{9}$ Conversely, the primary sclerosing cholangitis cases showed significantly less inflammation and lacked the perivenular lymphoplasmacytic accentuation. Importantly, portal inflammatory 
Table 3 Comparative histological features

\begin{tabular}{|c|c|c|c|}
\hline & $\begin{array}{l}\text { IgG4-associated } \\
\text { cholangitis } \mathrm{n}=10\end{array}$ & $\begin{array}{l}\text { Primary sclerosing } \\
\text { cholangitis } \mathrm{n}=17\end{array}$ & $P$-value \\
\hline Portal inflammation $>=2$ & $7(70 \%)$ & $3(18 \%)$ & 0.06 \\
\hline Interface hepatitis & $7(70 \%)$ & $5(29 \%)$ & 0.1 \\
\hline Lobular inflammation & $7(70 \%)$ & $2(12 \%)$ & 0.009 \\
\hline Perivenular inflammation in portal tracts & $5(50 \%)$ & $3(18 \%)$ & 0.05 \\
\hline Portal inflammatory nodules & $5(50 \%)$ & $0(0 \%)$ & 0.001 \\
\hline Zone 3 inflammation & $3(30 \%)$ & $1(6 \%)$ & 0.2 \\
\hline Plasma cells present & $9(90 \%)$ & $4(24 \%)$ & 0.001 \\
\hline Eosinophils present & $9(90 \%)$ & $6(35 \%)$ & 0.03 \\
\hline Bile duct injury & $5(50 \%)$ & $13(76 \%)$ & NS \\
\hline Periductal fibrosis & $4(40 \%)$ & $6(35 \%)$ & NS \\
\hline Bile duct loss & $0(0 \%)$ & $1(6 \%)$ & NS \\
\hline Hepatic fibrosis stage $>2$ & $1(10 \%)$ & $4(24 \%)$ & NS \\
\hline IgG4 plasma cells > 10 per HPF & $6 / 10(60 \%)$ & $0 / 12(0 \%)$ & 0.02 \\
\hline IgG4 plasma cells $>=1$ per HPF & $8 / 10(80 \%)$ & $1 / 12(8.3 \%)$ & 0.004 \\
\hline IgG4/IgG ratio $>=0.2$ & $7 / 10(70 \%)$ & $1 / 12(8.3 \%)$ & 0.006 \\
\hline
\end{tabular}

HPF, high power field; IgG, immunoglobulin G; NS, non-significant.
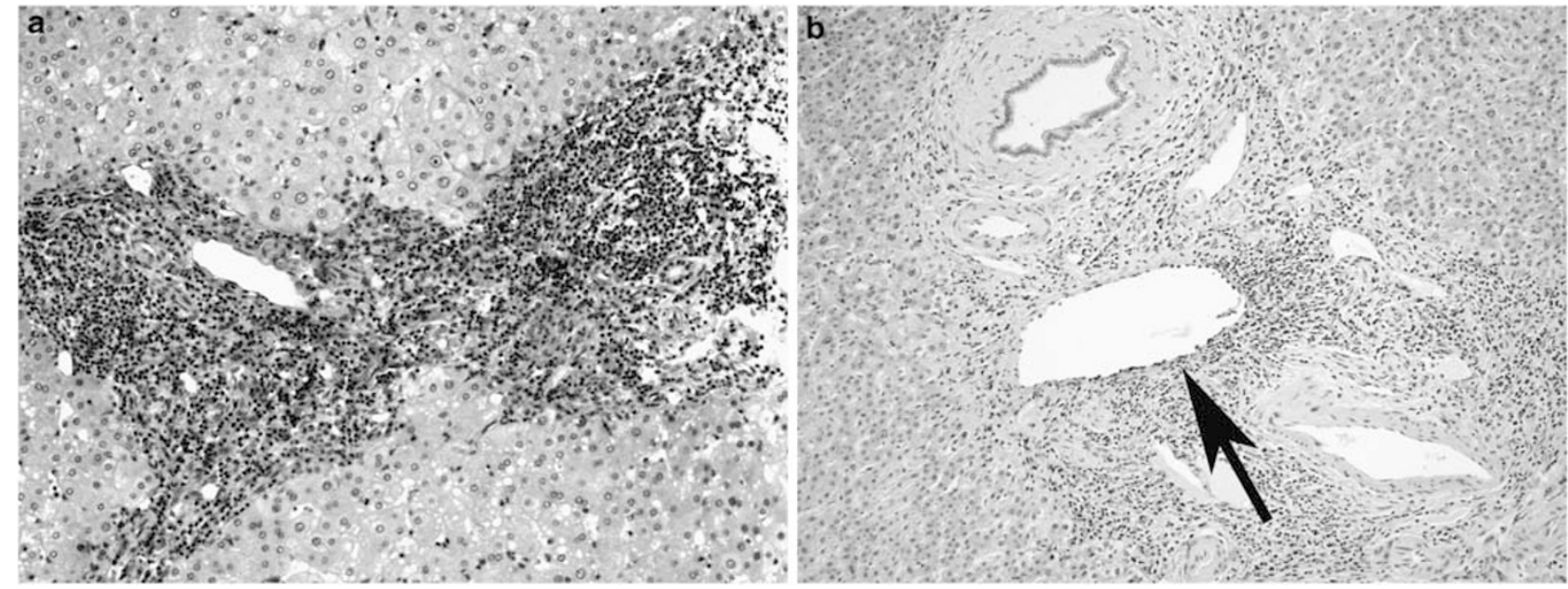

Figure 3 (a) Dense portal inflammation with IgG4-associated cholangitis. (b) IgG4-associated cholangitis with perivenular accentuation of inflammation (arrow).
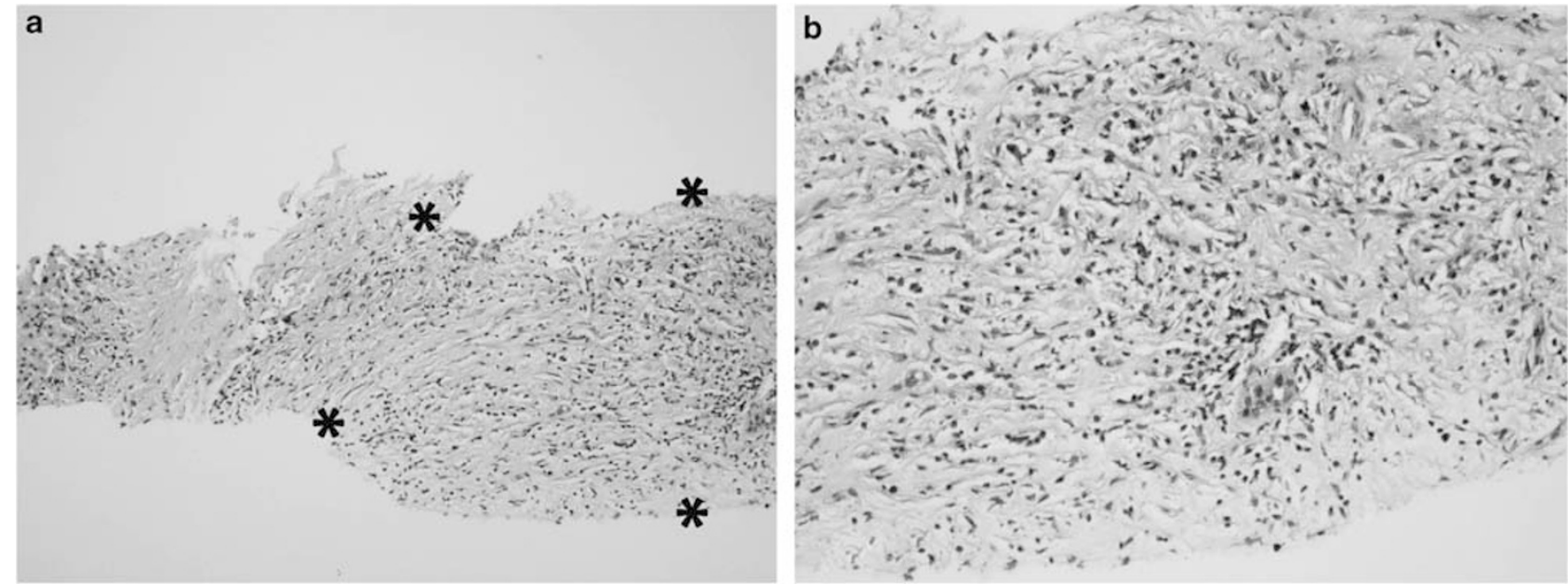

Figure 4 (a) Inflammatory nodule in a biopsy sample obtained from an individual with IgG4-associated cholangitis (a) (*highlights the outlines of this expansive nodule). (b) Higher power demonstrating spindle-shaped fibroblasts, lymphocytes, and plasma cells. 
nodules, observed in half of IgG4-associated cholangitis biopsy samples, were absent in the primary sclerosing cholangitis cohort. Finally, 6 of the 10 IgG4-associated cholangitis cases (1 was not a biopsy) showed >10 IgG4-positive cells per HPF compared with none in the primary sclerosing cholangitis group. On the basis of this series, albeit relatively small, it seems that a series of histological features may assist in distinguishing IgG4-associated cholangitis from primary sclerosing cholangitis on a liver biopsy.

Several recent series have described the hepatic manifestations of IgG4-associated cholangitis. ${ }^{7,13-17}$ The involvement of large bile ducts is characterized by a dense transmural inflammatory infiltrate resembling that observed in the pancreas. ${ }^{7}$ Three Japanese studies have previously examined the biliary pathology of IgG4-associated cholangitis. ${ }^{12,17,18}$ In the largest series of 16 cases, ${ }^{12}$ the authors distinguished five histological patterns of involvement, namely (1) portal inflammation, (2) large duct damage, (3) portal sclerosis with scarce inflammation, (4) lobular hepatitis, and (5) cholestasis. Following this scheme, the majority of our cases would be included in the portal inflammatory group with varying degrees of concurrent lobular and cholestatic patterns. However, in all the three series, the liver biopsy findings were reported to be relatively nonspecific. Portal-based inflammatory nodules were not recognized in any of these studies.

In this study, we choose to study cases of IgG4-associated cholangitis with well-established pancreatic involvement by autoimmune pancreatitis. However, there have been well documented cases of IgG4-associated cholangitis without an overt involvement of the pancreas. ${ }^{6}$ In addition, in one series, $9 \%$ of primary sclerosing cholangitis patients had increased levels of IgG4 in the serum. ${ }^{19}$ Clinically, these patients differed from those without increased serum IgG4 levels by showing higher total bilirubin and alkaline phosphatase levels, and lower frequency of inflammatory bowel disease.

Two IgG4-associated cholangitis cases without apparent intrahepatic biliary involvement showed both a dense inflammatory infiltrate and IgG4positive plasma cells, one with > $>50$ IgG4-positive cells. This evidence, although anecdotal, raises a concern over ongoing smoldering hepatitis in individuals with autoimmune pancreatitis. It should be noted that 1 of our cases progressed to biliary type cirrhosis, as did 4 of 58 cases in the recent series by Ghazale et $a l^{6}$ Additional studies are required to address the long-term hepatic sequelae of IgG4-associated cholangitis and the role of longterm immunosuppressive therapy.

The presence of inflammatory nodules and IgG4positive plasma cells may allow for identification of the important subpopulation of sclerosing cholangitis patients who respond to steroid therapy, ie, IgG4associated cholangitis. For those biopsy samples that lack the inflammatory nodule, the histological findings could overlap with other forms of chronic hepatitis and cholestatic diseases, such as primary biliary cirrhosis. However, in the sole study that examined this issue, IgG4-positive plasma cells were not identified in any patients with IgG4associated cholangitis $(n=17)$, autoimmune hepatitis $(n=17)$, primary biliary cirrhosis $(n=22)$, primary sclerosing cholangitis $(n=7)$, or chronic viral hepatitis $(n=17) .{ }^{12}$ In contrast, in the same study, tissue IgG4-positive plasma cells were identified in $47 \%$ of IgG4-associated cholangitis cases. ${ }^{12}$ Thus, an IgG4 stain is of considerable diagnostic value when confronted with liver biopsy obtained from an individual in whom primary sclerosing cholangitis is being clinically considered.

We acknowledge the fact that the size of our cohort may be a limiting factor. Nevertheless, this is the first North-American histological description of this emerging disease. Furthermore, autoimmune pancreatitis is a uncommon disease, the largest surgical series, a multicentric study, included only 62 autoimmune pancreatitis cases. ${ }^{20}$ Additional studies are required to understand the natural history of this hepatobiliary disease in individuals with concurrent pancreatic disease, and in those who lack pancreatic involvement, but whose liver biopsy samples show histological or immunological features of IgG4-associated cholangitis.

\section{Disclosure/conflict of interest}

The authors declare no conflict of interest.

\section{References}

1 Lee YM, Kaplan MM. Primary sclerosing cholangitis. N Engl J Med 1995;332:924-933.

2 Maggs JR, Chapman RW. Sclerosing cholangitis. Curr Opin Gastroenterol 2007;23:310-316.

3 Abdalian R, Heathcote EJ. Sclerosing cholangitis: a focus on secondary causes. Hepatology 2006;44:1063-1074.

4 Bjornsson E. Immunoglobulin G4-associated cholangitis. Curr Opin Gastroenterol 2008;24:389-394.

5 Gossard AA, Angulo P, Lindor KD. Secondary sclerosing cholangitis: a comparison to primary sclerosing cholangitis. Am J Gastroenterol 2005;100:1330-1333.

6 Ghazale A, Chari ST, Zhang L, et al. Immunoglobulin G4-associated cholangitis: clinical profile and response to therapy. Gastroenterology 2008;134:706-715.

7 Zen Y, Harada K, Sasaki M, et al. IgG4-related sclerosing cholangitis with and without hepatic inflammatory pseudotumor, and sclerosing pancreatitisassociated sclerosing cholangitis: do they belong to a spectrum of sclerosing pancreatitis? Am J Surg Pathol 2004;28:1193-1203.

8 Scheuer PJ, Lefkowitch JH. Liver Biopsy Interpretation, 7th edn, Vol. Liver Biopsy Interpretation, WB Saunders, 2005.

9 Deshpande V, Chicano S, Finkelberg D, et al. Autoimmune pancreatitis: a systemic immune complex mediated disease. Am J Surg Pathol 2006;30:1537-1545. 
10 Cornell LD, Chicano SL, Deshpande V, et al. Pseudotumors due to IgG4 immune-complex tubulointerstitial nephritis associated with autoimmune pancreatocentric disease. Am J Surg Pathol 2007;31: 1586-1597.

11 Deshpande V, Mino-Kenudson M, Brugge W, Lauwers GY. Autoimmune pancreatitis: more than just a pancreatic disease? A contemporary review of its pathology. Arch Pathol Lab Med 2005;129:1148-1154.

12 Umemura T, Zen Y, Hamano $\mathrm{H}$, et al. Immunoglobin G4-hepatopathy: association of immunoglobin G4bearing plasma cells in liver with autoimmune pancreatitis. Hepatology 2007;46:463-471.

13 Nakazawa T, Ohara H, Sano H, et al. Cholangiography can discriminate sclerosing cholangitis with autoimmune pancreatitis from primary sclerosing cholangitis. Gastrointest Endosc 2004;60:937-944.

14 Takikawa H, Takamori Y, Tanaka A, Kurihara H, Nakanuma Y. Analysis of 388 cases of primary sclerosing cholangitis in Japan; presence of a subgroup without pancreatic involvement in older patients. Hepatol Res 2004;29:153-159.
15 Nishino $\mathrm{T}$, Toki $\mathrm{F}$, Oyama $\mathrm{H}$, et al. Biliary tract involvement in autoimmune pancreatitis. Pancreas 2005;30:76-82.

16 Kamisawa T, Nakajima H, Egawa N, et al. IgG4-related sclerosing disease incorporating sclerosing pancreatitis, cholangitis, sialadenitis and retroperitoneal fibrosis with lymphadenopathy. Pancreatology 2006;6:132-137.

17 Hirano K, Shiratori Y, Komatsu Y, et al. Involvement of the biliary system in autoimmune pancreatitis: a followup study. Clin Gastroenterol Hepatol 2003;1:453-464.

18 Nishino T, Oyama H, Hashimoto E, et al. Clinicopathological differentiation between sclerosing cholangitis with autoimmune pancreatitis and primary sclerosing cholangitis. J Gastroenterol 2007;42:550-559.

19 Mendes FD, Jorgensen R, Keach J, et al. Elevated serum IgG4 concentration in patients with primary sclerosing cholangitis. Am J Gastroenterol 2006;101:2070-2075.

20 Zamboni G, Luttges J, Capelli P, et al. Histopathological features of diagnostic and clinical relevance in autoimmune pancreatitis: a study on 53 resection specimens and 9 biopsy specimens. Virchows Arch 2004;445:552-563. 